\title{
Case report: multiple and atypical amoebic cerebral abscesses resistant to treatment
}

\author{
Joaquin Alvaro Victoria-Hernández ${ }^{1}$, Anayansi Ventura-Saucedo², Aurelio López-Morones ${ }^{3}$, \\ Sandra Luz Martínez-Hernández ${ }^{4}$, Marina Nayeli Medina-Rosales ${ }^{4}$, Martín Muñoz-Ortega ${ }^{5}$, \\ Manuel Enrique Ávila-Blanco ${ }^{4}$, Daniel Cervantes-García ${ }^{6,7}$, Luis Fernando Barba-Gallardo ${ }^{8}$ and \\ Javier Ventura-Juárez ${ }^{4^{*}}$ (D)
}

\begin{abstract}
Background: The parasite Entamoeba histolytica is the causal agent of amoebiasis, a worldwide emerging disease. Amebic brain abscess is a form of invasive amebiasis that is both rare and frequently lethal. This condition always begins with the infection of the colon by E. histolytica trophozoites, which subsequently travel through the bloodstream to extraintestinal tissues.

Case presentation: We report a case of a 71-year-old female who reported an altered state of consciousness, disorientation, sleepiness and memory loss. She had no history of hepatic or intestinal amoebiasis. A preliminary diagnosis of colloidal vesicular phase neurocysticercosis was made based on nuclear magnetic resonance imaging (NMRI). A postsurgery immunofluorescence study was positive for the $140 \mathrm{kDa}$ fibronectin receptor of $E$. histolytica, although a serum analysis by ELISA was negative for lgG antibodies against this parasite. A specific E. histolytica 128 bp rRNA gene was identified by PCR in biopsy tissue. The final diagnosis was cerebral amoebiasis. The patient underwent neurosurgery to eliminate amoebic abscesses and was then given a regimen of metronidazole, ceftriaxone and dexamethasone for 4 weeks after the neurosurgery. However, a rapid decline in her condition led to death.
\end{abstract}

Conclusions: The present case of an individual with a rare form of cerebral amoebiasis highlights the importance of performing immunofluorescence, NMRI and PCR if a patient has brain abscess and a poorly defined diagnosis. Moreover, the administration of corticosteroids to such patients can often lead to a rapid decline in their condition.

Keywords: Cerebral amoebiasis, Entamoeba histolytica, NMRI, PCR, $140 \mathrm{kDa}$ fibronectin receptor, Brain abscess

\section{Background}

Entamoeba histolytica is the causal agent of amoebiasis, an emerging disease found worldwide [1]. This disease is prevented by improving sanitation. Although usually manifested in the human intestine [2], this agent can spread to the liver or brain and generate abscesses. Over 25 years ago, the molecular characterization of $E$.

\footnotetext{
* Correspondence: jventur@correo.uaa.mx

${ }^{4}$ Departamento de Morfología, Centro de Ciencias Básicas, Universidad

Autónoma de Aguascalientes, Ed. 202 Av Universidad \# 940, Ciudad

Universitaria, CP 20131 Aguascalientes, AGS, Mexico

Full list of author information is available at the end of the article
}

histolytica [3] provided an epidemiological pyramid in which $10 \%$ of the world population is infected by a noninvasive form of the parasite and $1 \%$ by an invasive form [2]. According to epidemiological evidence from PCR, amoebiasis ranks among the 20 most common causes of death in Mexico [1].

Cerebral amoebiasis, a very rare form of the disease, is often difficult to diagnose due to the limited availability of proper diagnostic tools. This disease has rarely been reported (see the following reviews: [4-6]), with only 133 documented cases [7-10], which chiefly occurred in

(c) The Author(s). 2020 Open Access This article is licensed under a Creative Commons Attribution 4.0 International License, which permits use, sharing, adaptation, distribution and reproduction in any medium or format, as long as you give appropriate credit to the original author(s) and the source, provide a link to the Creative Commons licence, and indicate if changes were made. The images or other third party material in this article are included in the article's Creative Commons licence, unless indicated otherwise in a credit line to the material. If material is not included in the article's Creative Commons licence and your intended use is not permitted by statutory regulation or exceeds the permitted use, you will need to obtain permission directly from the copyright holder. To view a copy of this licence, visit http://creativecommons.org/licenses/by/4.0/ The Creative Commons Public Domain Dedication waiver (http://creativecommons.org/publicdomain/zero/1.0/) applies to the data made available in this article, unless otherwise stated in a credit line to the data. 
young and middle-aged adults (22-65 years old) suffering from hepatic abscess or intestinal amoebiasis. The associated symptoms are headaches, altered mental status, meningeal disorders, seizure and vomiting. Of the 133 cases in the literature, 10 were given a timely diagnosis and adequate treatment (metronidazole and dehydroemetine), resulting in complete recovery [7]. In the other cases, it was not possible to make an accurate diagnosis. Consequently, proper therapy was not provided, and the patients died [10]. In Japan, a country with excellent public health measures, persons found to have cerebral amoebiasis are offered highly efficacious treatments that often lead to total recovery $[7,8]$. We herein present a case report of cerebral abscesses caused by $E$. histolytica in a woman with no history of hepatic or intestinal amoebiasis. Her clinical condition very rapidly declined and ended in death.

\section{Case presentation}

The 71-year-old female was a healthy housewife with no record of medical interventions. She had a family history of cerebral cancer. August 4, 2018, marked the onset of a series of symptoms, including an altered state of consciousness, disorientation and sleepiness and no presence of fever. She first consulted a doctor in private practice and was diagnosed with transient cerebral ischemia. The onset of memory loss and the persistence of the previous symptoms led the patient to seek medical attention in a public hospital where she was admitted and blood analysis was performed. The only alteration in the basic blood panel was high blood pressure, with a value of $149 / 100 \mathrm{mmHg}$. Pallor was observed in the skin and integuments. Neurological examination only showed cognitive impairment with bradypsychia, disorientation in time and space and difficulty in carrying out simple calculations, with no fever or meningeal signs. Nuclear magnetic resonance imaging using gadolinium contrast (NMRI) of the brain revealed multiple bilateral cystic lesions containing varying amounts of fluid (white arrows in Fig. 1Ab). The lesions were detected in several brain locations: the frontal, temporal and occipital lobes (Fig. $1 \mathrm{Aa}-\mathrm{d}$ ) and in the supra- and infratentorial zones (Fig. $1 \mathrm{Ba}-\mathrm{d})$. Since some of the lesions were compatible with a diagnosis of colloidal vesicular phase neurocysticercosis, because the hospital did not have a stereotaxic frame and due to the multiple locations of the abscesses, the patient was submitted to a right temporal craniotomy under general anesthesia on August 25, 2018. The layers of tissue were separated, working from the skin to the brain and through the superior temporal sulcus. A cyst (without capsule) was removed from the right temporal lobe, which had a diameter of approximately $5 \mathrm{~mm}$, contents with a milky not suppurative aspect and a periphery composed of soft whitish tissue (see supplementary video). A fragment of biopsy-extracted tissue was fixed in formaldehyde at $10 \%$ to be processed for histopathological examination. The surgical lesion was closed in layers from the dura to the skin.
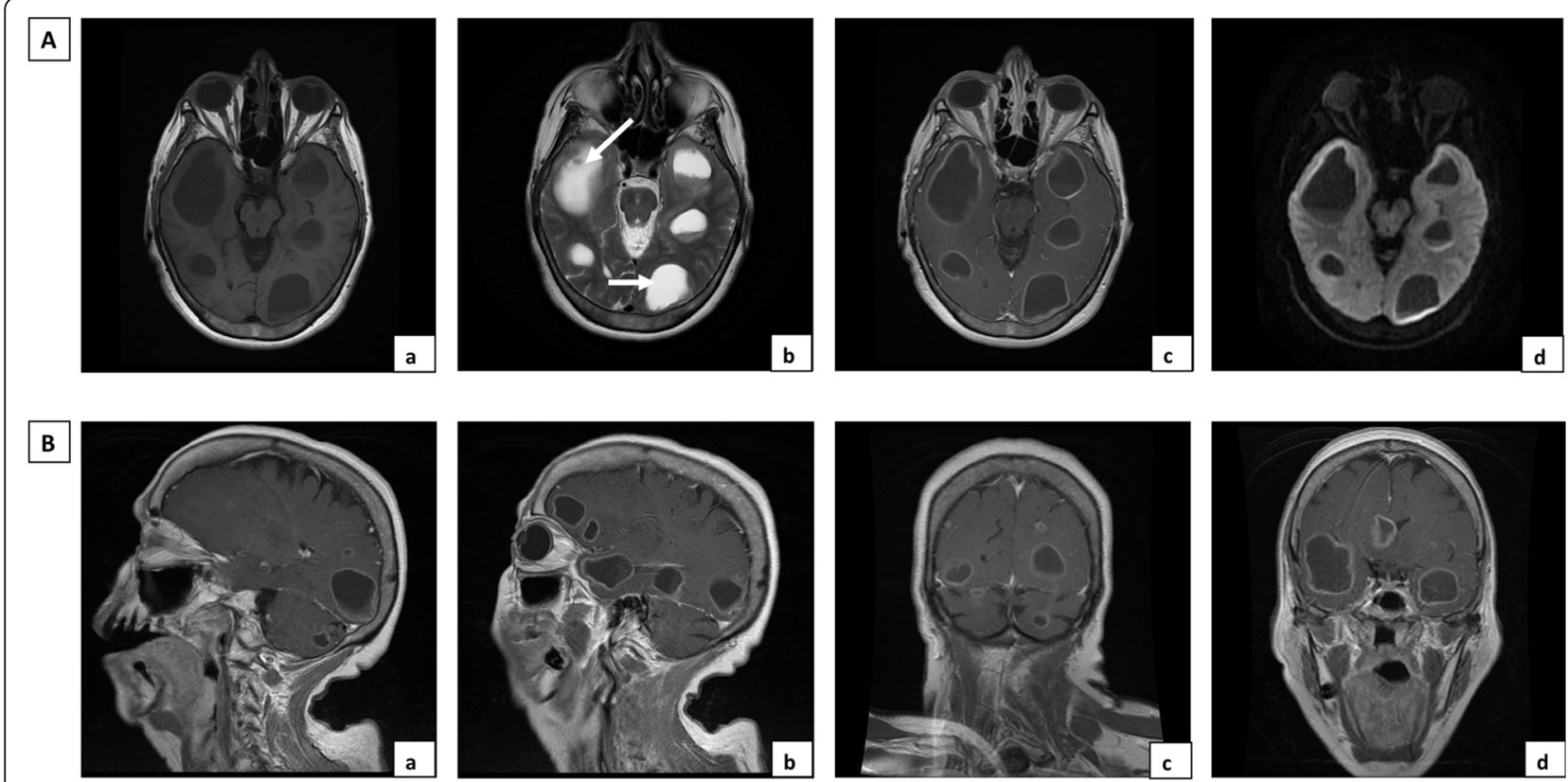

Fig. 1 Cranial nuclear magnetic resonance image. A. Multiple cystic lesions with ring enhancement after contrast administration, without restricted diffusion, in temporal and occipital lobes. (a) Axial T1SE, (b) Axial T2 Propeller, (c) Axial T1 SE + gadolinium, (d) Axial DWI. B. Gadolinium contrast brain NMRI showing ring-enhanced lesions with multilobar distribution. (a) and (b) Sagittal T1 SE + gadolinium, (c) coronal T1 SE + gadolinium with supraand infratentorial lesions, (d) coronal T1 SE + gadolinium with temporal and intraventricular lesions 
The patient was discharged on September 3, 2018 with a diagnosis of probable neurocysticercosis and possible hydatid cysts. The sample was not grown in bacterial culture, and the medical ethics committee decided to perform a histopathological study and ELISA to obtain a definitive diagnosis.

Brain biopsy tissue showed a large necrotic area with an amoeboid structure (red arrow) on the periphery of the brain tissue abscess (Fig. 2). The presence of E. histolytica trophozoites in cerebral biopsy specimens was confirmed by immunohistochemistry using a rabbit polyclonal anti-E. histolytica antibody [11] (Fig. 3a) and mouse anti-140 kDa fibronectin (FN)-binding protein (EhFNR) [12] (Fig. 3c). Furthermore, staining with rhodamine phalloidin revealed amoebic structures rich in actin filaments that formed adhesion plaques and macropinosomes (Fig. 3b, yellow arrows). The rest of the brain tissue was positive for glial fibrillary acidic protein (GFAP) (Fig. 3d) by immunofluorescence.

The presence of E. histolytica in the cerebral tissue was corroborated by PCR, and an $128 \mathrm{bp}$ amplicon of the E. histolytica rRNA gene (NCBI Accession number X65163.1) was cloned from cerebral tissue with the CloneJET PCR Cloning Kit (Thermo Scientific). DNA sequencing was performed in the Unit of Molecular Biology of the Institute of Cellular Physiology (National Autonomous University of Mexico) (Fig. 4). Interestingly, the ELISA of the patient serum did not find IgG antibodies against $E$. histolytica or amoebic proteins. Absorbance data analysis showed a cutoff for the negative control of 186.38; the median for amoebic cerebral abscess patients was 111.5 , a number below that of the negative control; however, the median for the positive

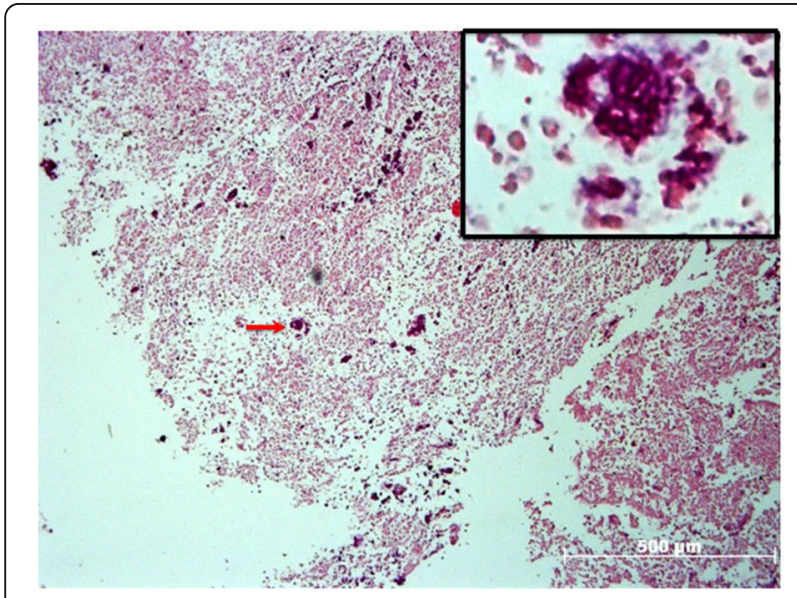

Fig. 2 E. histolytica trophozoites are revealed in amoebic brain abscesses by histopathological study. A broad area of necrotic nerve tissue can be observed. Trophozoites are widely distributed in the abscess (red arrow), as illustrated by the light microscopic images (X50). An amoebic trophozoite is shown with H\&E staining (box in the upper right corner, $\mathrm{X} 400$ ) control was 477.3 (Fig. 5a and b). Based on a diagnosis of amoebic brain abscess, the patient was treated with ceftriaxone ( $2 \mathrm{~g}$ IV every $12 \mathrm{~h}$ ), metronidazole $(750 \mathrm{mg}$ IV every $8 \mathrm{~h}$ ), and dexamethasone (8 $\mathrm{mg}$ IV every $8 \mathrm{~h}$ ) for 4 weeks, and no antiepileptic drugs were administered. A deteriorating condition led to her readmission to the hospital on October 14, 2018, and she died four days later.

\section{Discussion and conclusion}

Amoebic brain abscess is considered to occur in individuals with associated infections [13]. The current case began with signs of neurological alterations, muscle weakness, loss of memory and disorientation but without fever, diarrhea or amebic damage to the intestines or liver. Due to the absence of associated infections, this case was very different from the cases described by Orbison et al. [4] and Petri and Haque [6].

The surprising inability of the humoral immune response to detect $E$. histolytica prevented the organism from eliminating the trophozoites present in the brain; however, the identification of amoebic trophozoites was performed by applying a specific polyclonal monospecific $140 \mathrm{kDa}$ amoebic protein antibody that acts as a fibronectin receptor [12].

In response to a diagnosis of probable neurocysticercosis and possible hydatid cysts, the patient received metronidazole and dexamethasone during the last 4 weeks of her life. The administration of metronidazole was successful in treating individuals with amoebic cerebral abscesses [7, 8, 14, 15]. However, some cases have been treated with intravenous and oral metronidazole without positive results [9] in patients where treatment is not effective, and the aggravating factor may be the poor state of health of the patient.

However, the use of prednisolone in our patient apparently had a negative effect, consistent with a recent review by Shirley and Moonah [16]. Of 525 case reports of fulminant amoebic colitis, 24 of the subjects received corticosteroid therapy. However, 14 (58\%) were incorrectly diagnosed with inflammatory colitis and underwent a very rapid progression of amoebiasis.

In our case, the patient's clinical features were insidious, and several laboratory and cabinet studies had to be carried out to obtain a precise diagnosis of cerebral amebiasis in such a way that the intravenous metronidazole did not eliminate the parasite and the patient died. Similar cases have been reported by Akhaddar [17]. Furthermore, Bansal et al. [18] and Ehrenkaufer et al. [19] reported a partial resistance of the parasite to the treatment, and Petri and Haque [6] observed that $40-60 \%$ of the treated patients maintained the parasite in the colon lumen. 
a

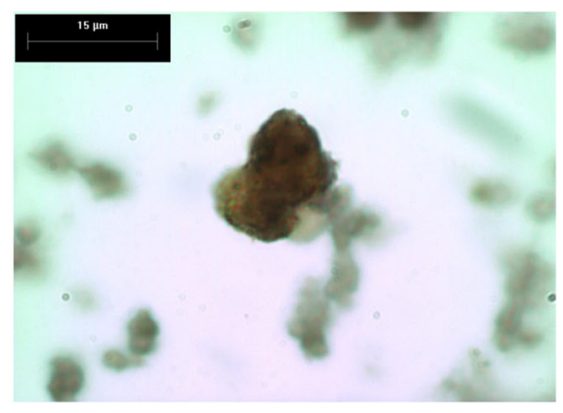

c

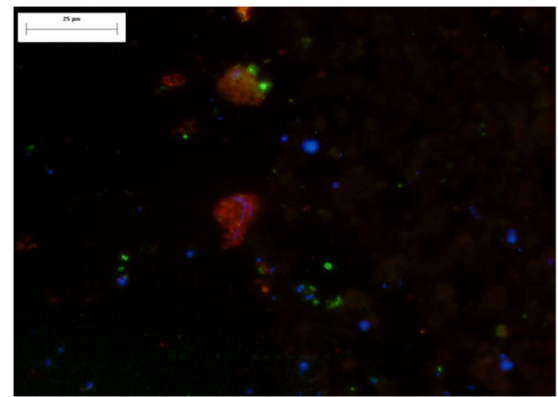

b

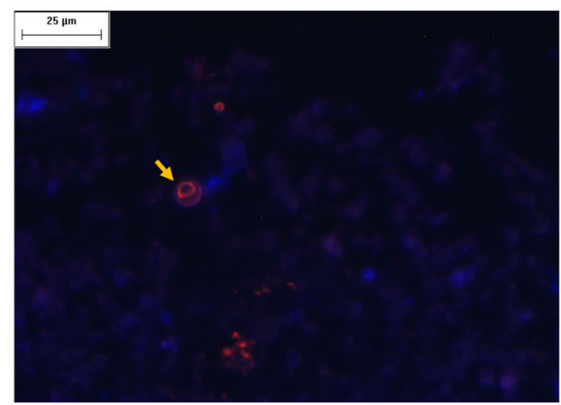

d

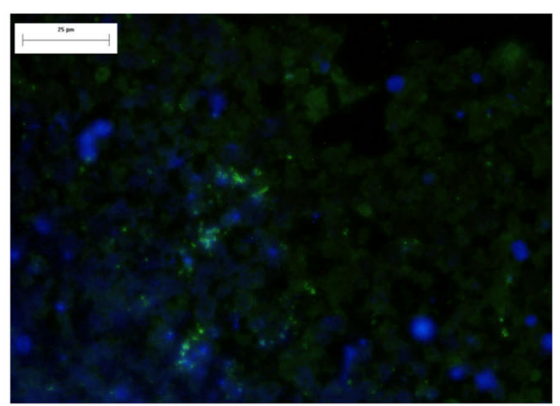

Fig. 3 Immunodetection of E. histolytica trophozoites in brain tissue by immunohistochemistry and immunofluorescence. Identification of the E. histolytica 140 kDa fibronectin (FN)-binding protein (EhFNR) and glial fibrillary acidic protein (GFAP) in brain tissue by immunofluorescence. a Amoebic trophozoites stained using peroxidase-labeled rabbit anti-E. histolytica polyclonal antibody $(X$ 1000). b E. histolytica actin cytoskeleton dynamics and distribution in amebic brain abscesses. Actin was stained with rhodamine-phalloidin (1:40, red), forming plate adhesions, as shown by the yellow arrow (X 400). c E. histolytica trophozoites stained positive for EhFNR (red), GFAP (green) and nuclei (Hoechst 1:1000, blue) in amebic brain abscess tissue (X400). d GFAP-immunoreactive cells in brain sections (green) and nuclei (blue) (X400)
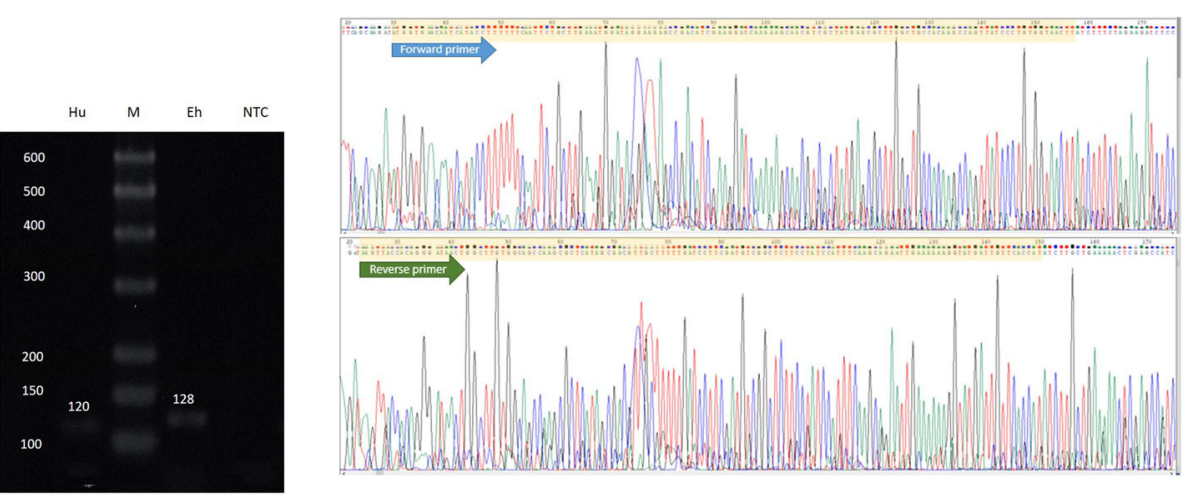

$128 \mathrm{pb}$ band sequence for rRNA $28 \mathrm{~S}$ gene of $E$. histolytica ATGGTGAACAATCATACCTTTTTTCAATTCTGCTTGAAATGGATAGGAAGAGCCGA CATCGAAGGATCAAAAAGCAACGTCGCTATGAGCGCTTGGCTGCCACAAGCCAGTT ATCCCTGTGGTAACTT

Fig. 4 PCR, cloning and sequencing. Total DNA was extracted from $100 \mathrm{mg}$ paraffin-embedded cerebral tissue using the Wizard Genomic DNA purification kit (Promega, Madison, WI, USA). DNA was quantified in a NanoDrop 2000 (Thermo Scientific, Waltham, MA, USA), obtaining an E. histolytica $128 \mathrm{bp}$ amplicon for the rRNA gene, which was cloned with the CloneJET PCR Cloning Kit (Thermo Scientific) using a pJET1.2/blunt cloning vector. Then, the ligation mixture was used for transformation of Escherichia coli DH5a calcium-competent cells. Plasmid DNA was extracted from heat-shocked cells with the Zyppy Plasmid Miniprep (Zymo Research, Irvine, CA, USA). Clones were analyzed by PCR to verify the insertion of the amplicon into the pJET1.2/blunt vector. The plasmid sequence shows forward and reverse primers (electropherograms) that correspond to the $E$. histolytica rRNA gene sequence. $\mathrm{Hu}=120 \mathrm{bp}$ amplicon for human $\beta$-actin; $\mathrm{M}=\mathrm{bp}$ marker; $\mathrm{Eh}=128 \mathrm{bp}$ amplicon for the $E$. histolytica rRNA $18 \mathrm{~s}$ gene, NTC = no template control 
a
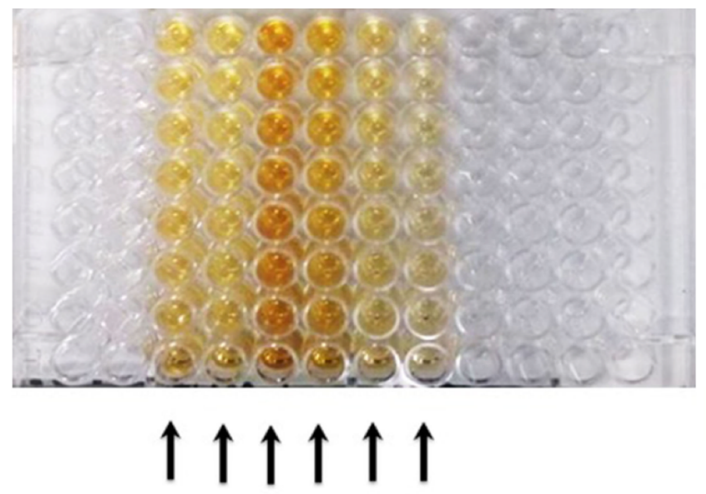

$\begin{array}{llllll}1 & 2 & 3 & 4 & 5 & 6\end{array}$ b

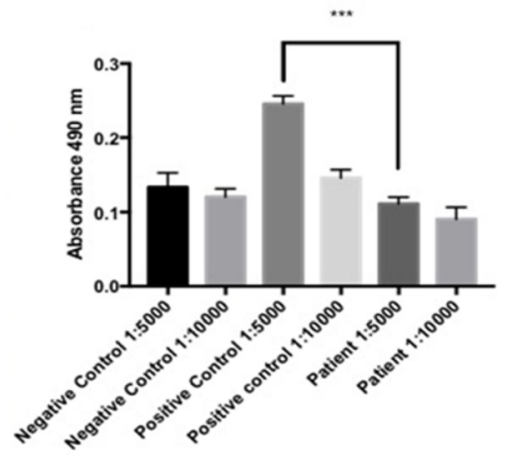

Fig. 5 ELISA. a The ELISA plate displays a slight reaction to a negative control $(1,1: 5000 ; 2,1: 10000)$. The positive reaction is evident from the application of anti-E. histolytica antibodies to the serum of an individual with amoebic liver abscess $(3,1: 5000 ; 4,1: 10000)$. There was a negative reaction to anti-E. histolytica antibodies in the serum of the patient under study despite the presence of brain abscesses $(5,1: 5000 ; 6,1: 10000)$. $\mathbf{b}$ The graph shows the significant difference between the positive control $(1: 5000)$ and the patient in the current case study $(1: 5000)(* * *)$ ANOVA

Our patient did not have a history of hepatic or intestinal amoebiasis, and serum analysis was negative for IgG antibodies against E. histolytica. This result illustrates the importance of adopting a series of basic laboratory tests, including immunofluorescence, NMRI and PCR, for patients with brain abscesses. Moreover, it must be taken into account that the administration of corticosteroids to such patients has often led to a rapid decline in their condition.

\section{Abbreviations}

E. histolytica: Entamoeba histolytica; ELISA: enzyme-linked immunosorbent assay; NMRI: nuclear magnetic resonance imaging; CD59: protectin; PCR : polymerase chain reaction

\section{Acknowledgments}

We thank Dr. Quintanar-Stephano Jose Luis of Universidad Autónoma de Aguascalientes, Mexico, for donating the GFAP antibody and Dr. TalamásRohana Patricia of CINVESTAV-IPN, Mexico for donating the $140 \mathrm{kDa}$ antibody.

\section{Authors' contributions}

Patient management was carried out by LMA and the case report preparation by VHJA and VSA. Design, acquisition, analysis and interpretation of morphological and ELISA data were carried out by MRMN and ABME. DNA Extraction from cerebral tissue, integrity analysis and PCR development were done by MOMH. The literature review was conducted by VJJ and BGLF. $\mathrm{PCR}$ analysis for sequencing was performed by CGD, and the manuscript and references were elaborated by VJJ, finally, MHSL have drafted the work and substantively revised it. All authors have read and approved the final version of the manuscript.

\section{Funding}

The present study was supported by the Consejo Nacional de Ciencia y Tecnología, Mexico (CONACYT, grant \#286184), which is the source of federal funds for research activities in Mexico. UAA PIBB 16-2 is the registration number of the current project in the Universidad Autónoma de Aguascalientes, Mexico, an institution that also contributed financial resources for the study.

\section{Availability of data and materials}

The most relevant data generated or analyzed during the current study are included in this report. Additional data examined by neurosurgery to eliminate amoebic abscesses are available in the video "Cerebral amebiasis" at https://www.synapse.org/\#!Synapse:syn22236751, DOI: https://doi.org/10. 7303/syn22236751.1, https://doi.org/10.7303/syn22236751.1

\section{Ethics approval and consent to participate}

The treatment of the patient and permission to elaborate a case report was approved by Instituto Mexicano del Seguro Social (IMSS), Office number 1, Official Mexican Standard NOM-004-SSA3-2012.

\section{Consent for publication}

Written informed consent was obtained from the patient's daughter for publication of this case report and any accompanying images. A copy of the written consent is available for review by the Editor of this journal.

\section{Competing interests}

The authors declare that they have no conflicts of interest.

\section{Author details}

'Departamento de Anatomía Patológica, Hospital General de Zona 3 IMSS Jesús María, Prolongación General Ignacio Zaragoza 905, Jesús María, CP 20908 Aguascalientes, AGS, Mexico. ${ }^{2}$ Departamento de Anestesiología, Hospital General de Zona 3 IMSS Jesús María, Prolongación General Ignacio Zaragoza 905, Jesús María, CP 20908 Aguascalientes, AGS, Mexico. ${ }^{3}$ Departamento de Neurocirugía, Hospital General de Zona 3 IMSS Jesús María, Prolongación General Ignacio Zaragoza 905, Jesús María, CP 20908 Aguascalientes, AGS, Mexico. ${ }^{4}$ Departamento de Morfología, Centro de Ciencias Básicas, Universidad Autónoma de Aguascalientes, Ed. 202 Av Universidad \# 940, Ciudad Universitaria, CP 20131 Aguascalientes, AGS, Mexico. ${ }^{5}$ Departamento de Química, Centro de Ciencias Básicas, Universidad Autónoma de Aguascalientes, CP 20131 Aguascalientes, AGS, Mexico. ${ }^{6}$ Departamento de Microbiología, Centro de Ciencias Básicas, Universidad Autónoma de Aguascalientes, CP 20131 Aguascalientes, AGS, Mexico. ${ }^{7}$ Consejo Nacional de Ciencia y Tecnología, CONACYT, 03940 Ciudad de México, Mexico. ${ }^{8}$ Departamento de Optometría, Centro de Ciencias de la Salud, Universidad Autónoma de Aguascalientes, CP 20131 Aguascalientes, AGS, Mexico. 
Received: 2 January 2020 Accepted: 2 September 2020

Published online: 14 September 2020

\section{References}

1. Ximénez C, Morán P, Rojas L, Valadez A, Gómez A. Reassessment of the epidemiology of amebiasis: state of the art. Infect Genet Evol. 2009;9:1023-32.

2. WHO. Amoebiasis. Wkly Epidemiol Rec. 1997;72:97-98.

3. Clark CG, Diamond LS. Entamoeba histolytica: a method for isolate identification. Exp Parasitol. 1993;77:450-5.

4. Orbison JA, Reeves N, Leedham CL, Blumberg JM. Amebic brain abscess; review of the literature and report of five additional cases. Medicine (Baltimore). 1951;30:247-82.

5. Lombardo L, Alonso P, Saenzarroyo L, Brandt H, Humbertomateos J. Cerebral amebiasis: report of 17 cases. J Neurosurg. 1964;21:704-9.

6. Petri WA, Haque R. Entamoeba histolytica brain abscess. Handb Clin Neurol. 2013;114:147-52.

7. Ohnishi K, Murata M, Kojima H, Takemura N, Tsuchida T, Tachibana H. Brain abscess due to infection with Entamoeba histolytica. Am J Trop Med Hyg. 1994:51:180-2.

8. Morishita A, Yamamoto $\mathrm{H}$, Aihara $\mathrm{H}$. A case of amebic brain abscess. No Shinkei Geka. 2007;35:919-25.

9. Castillo De La Cruz M, José Luis GB, Mendizábal Guerra R, Félix I, Rivas A Absceso cerebral multicéntrico causado por Entamoeba histolytica. Arch Neurocienc. 2004;9:59-62.

10. Maldonado-Barrera CA, Campos-Esparza Mdel R, Muñoz-Fernández L, Victoria-Hernández JA, Campos-Rodríquez R, Talamás-Rohana $\mathrm{P}$, et al. Clinical case of cerebral amebiasis caused by E. histolytica. Parasitol Res. 2012;110:1291-6.

11. Ventura-Juárez J, Campos-Rodríguez R, Tsutsumi V. Early interactions of Entamoeba histolytica trophozoites with parenchymal and inflammatory cells in the hamster liver: an immunocytochemical study. Can J Microbiol. 2002;48:123-31.

12. Talamás-Rohana P, Rosales-Encina JL, Gutiérrez MC, Hernández VI. Identification and partial purification of an Entamoeba histolytica membrane protein that binds fibronectin. Arch Med Res. 1992:23:119-23.

13. Rana TA, Hameed T, Rao N. Cerebral amoebiasis. J Pak Med Assoc. 1993;43: 78-80.

14. Tamer GS, Öncel S, Gökbulut S, Arisoy ES. A rare case of multilocus brain abscess due to Entamoeba histolytica infection in a child. Saudi Med J. 2015; 36:356-8.

15. Chou A, Austin RL. Entamoeba histolytica. In: StatPearls. Treasure Island, FL: StatPearls Publishing; 2020.

16. Shirley DA, Moonah S. Fulminant amebic colitis after corticosteroid therapy: a systematic review. PLoS Negl Trop Dis. 2016;10:e0004879.

17. Akhaddar A. Other parasitic infections of the central nervous system. In: Atlas of infections in neurosurgery and spinal surgery. Cham: Springer International Publishing; 2017. p. 311-6.

18. Bansal D, Malla N, Mahajan RC. Drug resistance in amoebiasis. Indian J Med Res. 2006;123:115-8.

19. Ehrenkaufer GM, Suresh S, Solow-Cordero D, Singh U. High-throughput screening of entamoeba identifies compounds which target both life cycle stages and which are effective against metronidazole resistant parasites. Front Cell Infect Microbiol. 2018;8:276.

\section{Publisher's Note}

Springer Nature remains neutral with regard to jurisdictional claims in published maps and institutional affiliations.

Ready to submit your research? Choose BMC and benefit from:

- fast, convenient online submission

- thorough peer review by experienced researchers in your field

- rapid publication on acceptance

- support for research data, including large and complex data types

- gold Open Access which fosters wider collaboration and increased citations

- maximum visibility for your research: over $100 \mathrm{M}$ website views per year

At $\mathrm{BMC}$, research is always in progress.

Learn more biomedcentral.com/submissions 